\title{
Köpeklerde sindirim kanalı hastalıklarının radyografik değerlendirmesi
}

\author{
Ali BUMİN ${ }^{1}$, Savaş ÖZTÜRK², Murat KIBAR ${ }^{3}$, M. Doğa TEMIZSOYLU ${ }^{4}$, Zeki ALKAN ${ }^{1}$ \\ 1 Ankara Üniversitesi, Veteriner Fakültesi, Cerrahi Anabilim Dalı, Ankara; 2 Kafkas Üniversitesi, Veterincr Fakiiltcsi. \\ Cerrahi Anabilim Dalı, Kars; ${ }^{3}$ Erciycs Üniversitesi, Veteriner Fakültesi, Cerrahi Anabilim Dalı, Kayseri; ${ }^{4}$ Akdeniz. Üniversitesi. \\ Burdur Veteriner Fakuiltesi, Cerrahi Anabilim Dalı, Burdur
}

Özet: Bu çalı̧̧̧a ile sindirim sistemi şikayeti ile getirilen köpcklerde sindirim kanalı hastalıklaumın raddyografïk de-

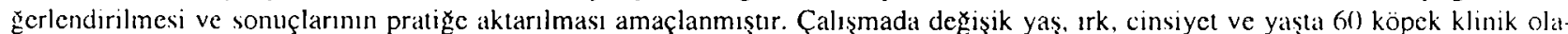
rak değerlendirildi. Olguların tiimiinde önce direkt radyografik muayene, daha sonra indirckt muayenc yapıldı. Radyografik muayencler sonunda; 10 olguda özefagusta, 36 olguda midede, 14 olguda da barsaklarda lezyonlara rastlandı. Sonuç olarak; sindirim kanalı hastalıklarının tanısında direkt ve indirekt muayeneler ile önemli bilgiler sałgladı. Direkt grafinin, sindirim kanalı hastalıklarında indirckt muayeneye göre yetersiz olduğu ve indirekt grafi ile sindirim kanalında obstruksiyon. dilatasyon. gastrik di. lattasyon-volvulus, ïlserler, yangılar, tümörler, rotasyonlar ve pilorik hastalıkların daha kolay değerlendirilcbilccẹ̆i ve kesin tanmın sas̆lanaca kanıstna varıldt.

Anahtar kclimeler: Köpek, radyografi, sindirim kanalı

\section{Radiographic evaluation of digestive system diseases in dogs}

Summary: The radiographic cvaluation of the dogs presented with the symptoms of digestive system discases systcm were made and their practical usage was aimed. In this study, 60 dogs of different age, sex and breed were used. Direct and indirect examination were made. Of the cases observed; 10 had lesions in oesophagus, 36 in stomach and 14 in intestine. In conclusion. for the diagnosis of the digestive system diseases some important knowledge has been gained by direct and indirect cxamination. Direct radiography is not sufficient to cvaluate digcstive system disorders, when it is compared with indirect examination. It is more practical and satisfying to use indirect radiography in such diseases as obstruction, dilatation, gastric dilatation-volvulus, ulcer inflammation, tumor, rotation and pyloric discases.

Kcy words: Digestive systcm, dog, radiography

\section{Giriş}

Sindirim sistemi hastalıklarının tanısında; anamne\%, inspcksiyon, palpásyon, oskultasyon, deneysel punksiyon, deneysel laparatomi, rektal muayenc, endoskopi, ultrasonografi, tomografi ve laboratuvar muayeneleri gibi tanı yöntemlerinden yararlanılır. Bu tanı yöntemleri arasunda önemli bilgiler sağlayan diğer bir yöntem de radyografik muayenedir. Sindirim kanalının radyografisinde direkt ve indirckt radyografik muayene yöntemlerinden yararlanılmaktadır $(1,4,6,11,12)$.

Sindirim kanalının radyografik muayenesine her zaman dirckt radyografiyle başlanmalıdır. Abdominal organlann pozisyonlannın belirlenmesi, sindirim kanalında herhangi bir opasitenin (yoğun feçes, gaz, yabancı cisim gibi) bulunup bulunmadığının araştırılması ve uygun radyografik yöntemin sıçilmesi amacıyla, daima direkt muayenenin, indirekt radyografik muayeneden önce yapılması önerilir $(2,10,13)$.

Gastro-intestinal radyografide; ventro-dorsal, dorsoventral, sağ latero-lateral, sol latero-lateral ve duruma göre bazen oblik pozisyonlarda grafiler alınmalıdır $(1,2,13,15,16)$
Direkt radyografik muayeneler ile sinırl bilgiler elde edilir. Çünkü, sindirim sistemini oluşturan organların radyografik dansiteleri abdominal boşlukta bulunan diğer organlarınkilere benzer $(2,5,13)$.

Sindirim kanalının radyografisinden önce hastanın hazırlanması önemlidir. Hasta, muayeneden yaklaşık 12 24 saat önce aç bırakılarak sindirim kanalının boşalması sağlanır. Siddetli hastalarda bu hazırlığı yapmak için vakit olmayabilir, ancak bu durumda kusma ve iştahsı\%lığa bağ̌lı olarak sindirin kanalı boşalmış olur. Kontrası maddenin ilerlemesini durdurabileceği veya yavaşlatabileceği için, genel anestezi kullanılmasından kaçınılmalıdır. Sedasyon kaçınılmaz olursa, acetylpromazine gibi phenotiazine deriveleri tercih edilmelidir $(2,4,10,13)$.

Daha ayruntılı bir inceleme yapmak gerekli olduğunda sindirim sisteminin indirekt radyografik muayenesi yapılmalıdır $(3,6,8,10,11)$.

Sindirim kanalının indirekt (kontrast) radyografisinde; baryum sülfat ve çeşitli iyotlu bileşiklerin kullanıldığı pozitif kontrast ve hava. $\mathrm{NO}_{2}, \mathrm{CO}_{2}$ gibi gazlarm kullanılmasıyla negatif kontrast ya da her ikisinin birlikle 
küllanıldı ğı çift kontrast radyografik muayene yöntcanlerinden yararlanılmakladur. Kontrast maddenin ve. rifmesinden sonra 1., 15., 30.. 60. ve 120. dakikalarda giatiler alınır. Egger gerekli olursa bir saat aralarla tekrablanir $(2.7,8,10,13)$.

Sindirim sisteminin radyografik muayenesinde farenks. özefagus, larenks, mide, ince ve kalın barsaklar ve kảaciğcrin sistematik olarak incelenmesi gerekir (7.12).

Özelagus, mide ve barsaklarda perforasyondan şiiphéli durumlardal, baryum suilfar yerine, yüksck ozmolar (jineglumine dialrizoate, sodyum diatrizoate) veya duişuk otmolar (iohexol) iodine preparatları kullanılmaktadır $(1.2,5.7,12)$.

Sindirim kanalına ait hastalıklar. kusma, kilo kaybı. regürgilasyon ve yutkunma güçliiği gibi klinik belirtilerlc orlilya flkar $(10,12)$. Özefagus un radyografik muayenesi ile: negaozcfagus, vaskiilcr ring anomalileri, yabạncı cisimler. özefagilis, özefageal neoplazma gibi anornịaliteler tespit cdilebilir $(6.12,13,17)$. Midenin radyografik muayenesi ile; pilorospazm, pilorik stenoz, yabanci cisimler, gastritis, iilser, ncoplazma ve mide rupturu gibi anormaliteler belirlenebilirken, barsaklarla ilgili olarak yabanci cisimler, linecr yabanci cisimler, nonülseratif ve iufscratif cntcritis, invaginasyon, intramural kitleler (neoplazma. apse, granuloma), intestinal perforasyon, megakolon ve kolitis gibi anormaliteler ortaya çikarılabilnekledir $(8,12-14)$.

Bu çalışma ile kliniğe sindirim sistemi şikayetiyle getrilen köpeklerde sindirin kanah hastalıklarının radypografik değerlendirilmesi ve sonuçlarmm pratiğe aktậrılnıası amaçlanmışır.

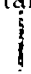

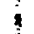

\section{Materyal}

Calışma materyalini Ankara Üniversitesi Veteriner fakiiiliesi Radyoloji Bilim Dalı Röntgen Ünitesine 199820()() yılları arasnda sindirim sistemi grafisi istemi ile ge trrilen değişik ırk, yaş ve cinsiyette 60 köpek oluşurdu.

: Radyografik muayencele $30 \mathrm{~mA}$ gücündeki Schimalzu marka röntgen cihazı kullanıldı. Kontrast madde ólarak RX suispansiyon \% 100 (baryum sülfat $240 \mathrm{~g} / 240$ ml. Yenişehir Lab.) ve Ürografin $\% 76$ (sodyumami-notrizoale $0.1 \mathrm{~g}$, meglumine amidotrizoate $0.66 \mathrm{~g} / \mathrm{ml}$, Schering) kullanılds.

\section{Metot}

Farinks' in radyografisi için, koyu baryum sülfat ve baryum suilfatla karıştırılnış yiyecek verilerek yutma sırasinda latero-lateral ve ventro-dorsal pozisyonlarda grafiler alind

Örefagusun grafisi için; konsantre baryum sülfat (10-20 ml) veya baryum suilfatla karıştırılmıs yiyecek ve- rilerek yutmayı takiben latero-lateral ve ventro-dorsal pozisyonlarda grafiler alındı. Alnan anamnezlerde perforasyondan şüpheleniliyorsa Urografin \%76 verilerck graliler alınd.

Midenin radyografisi için llık su ile \%,50) dilüe edilmiş baryum sülfat, $7-8 \mathrm{ml} / \mathrm{kg}$ dozunda ağızdan enjektör yardımıla ya da mide sondası aracılığıyla verildi. Perforasyon şuiphesi olduğunda Ürografin $1: 1$ oranmonda serum fizyolojik ile sulandirılarak $10 \mathrm{ml} / \mathrm{k}$ g dozunda $1 \mathrm{e}$ rildi. Daha sonra sol tatero lateral ve ventro-dorsal pozisyonlarda grafiler alındı. Gerekli olduğu durumlarda oblik pozisyonlar kullanıldı.

Ince barsakların radyografisi için, 1/4 oranunda sulandırılmış baryum sülfat $7-8 \mathrm{ml} / \mathrm{kg}$ dozunda à̧ı da mide lüpü aracılığıla verildi. Pertorasyon şüpheli ol. gularda $1: 1$ oranmda serum fizyolojik ile dilic edilmis Ürografin $10 \mathrm{ml} / \mathrm{kg}$ dozunda mide sondası yardmmyla ya da enjektörle ağızdan verildi.

Kalın barsaklarm radyografisi için kontrast madde. oral olarak ya da bazı durumlarda retrograd olarak ve rildi. Oral olarak 1/4 oranında sulandırılmı baryum sülfat 7-8 $\mathrm{ml} / \mathrm{kg}$ dozunda kullanıld. Sadece kalın harsaklarm inceleneceği durumlarda kontrast madde. sonda yardmuyla $10 \mathrm{ml} / \mathrm{kg}$ dozunda retrograd olarak verildi. Bar/1 olgularda lavman yapılarak kalın barsaklar hoşalululıklan sonra indirekı radyografik muayene yapıldı. Perfortasyondian şïpheli durumlarda 1:1 oranında serum lizyolojik ile sulandırılmıs Ürografin $10 \mathrm{ml} / \mathrm{kg}$ dozunda verildi. Kontrası maddenin verilmesinden sonra latero-lateral ve ventrodorsal pozisyonda grafiler alınds.

Mide. ince ve kalm barsak grafileri 12.24 sabllik açlık döneminden sonra alınd. Kontrast madde verildik ten sonra 1., 15., 30., 60. ve 120. dakikalirda graliler alın dı, gerekli olduğu durumlarda l saal aralıklarla tek rarlandl.

\section{Bulgular}

Radyografik muayencye ahnan tim olgularda istahsızlık, kilo kaybı, kusma v'c halsizlik gibi klinik be. lirtilere rastlandi. Radyografik muayenelerde farenks ilc ilgili lezyona rastlanmadı. Yapslan inceleme sonucunda: 10 olguda özefagus (\%17), 36 olguda mide (\%60), 14 olguda da barsaklarla (\%23) ilgili le yonlara rastlandi.

Özefagusla ilgili lezyon belirlenen 10 olgunun 5 'inde (\%50) özefagitis belirlendi. Özefagitis buluman bu olgularda kontrast maddenin mideye geçişinden sonra $6 z e-$ fagus mukozasi kontrast maddeyle swalı olarak izlendi. Özefagusta yabancı cisim belirlenen 4 olgunun (\%40) 3'ünde yabance cisimler direkt radyograficle radyoopak olarak izlendiği halde (Şekil 1), l olg̣uda hasla sahibinin 


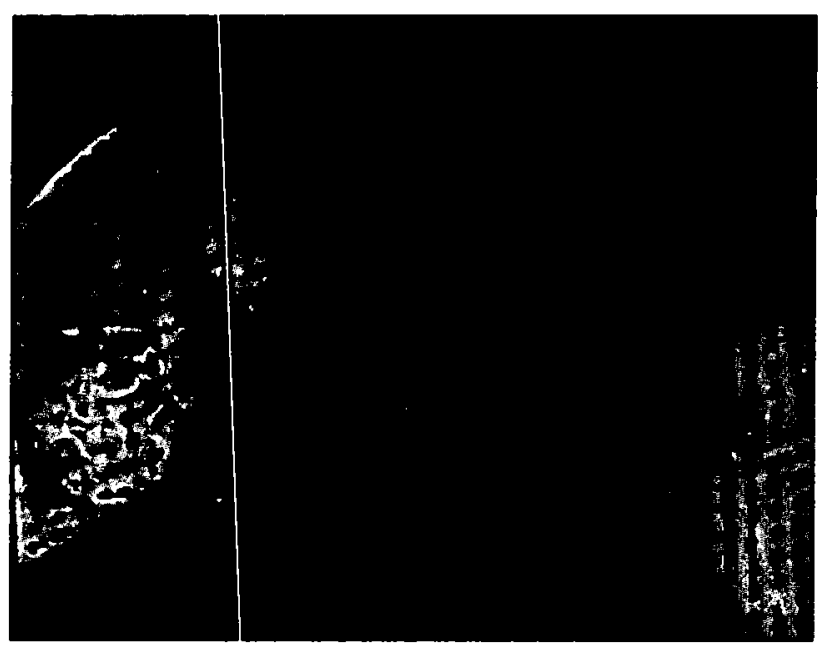

Sckil 1. Orcfatgusa radyoopak yabancı cisim (L/L radyografi). Finue 1. Ridlopaque lorcin: body in ocsophagus (1./L radioglaphys.

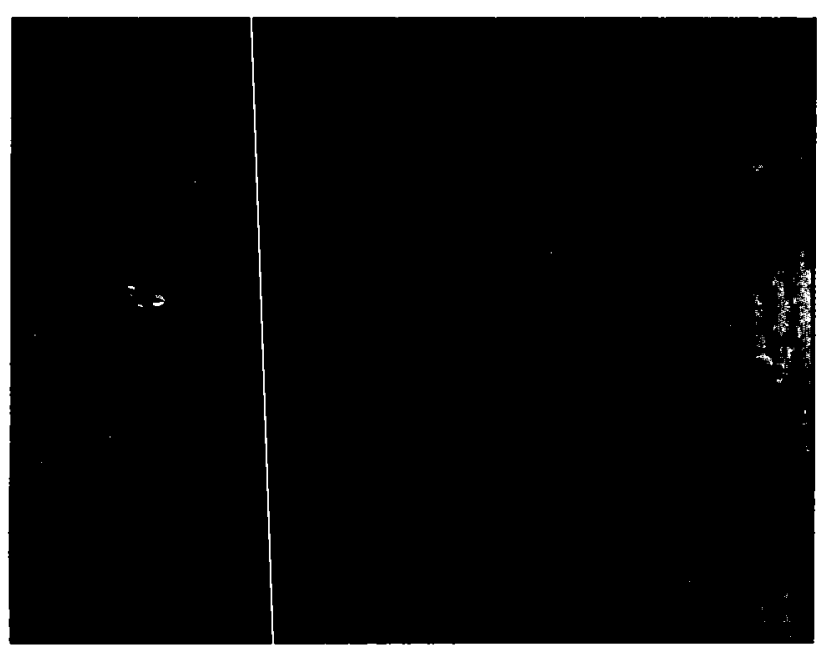

Schil 2. Ordingusta kontrast maddcyle sivalı radyolusent yal banci cisim ( $\mathrm{L} / \mathrm{L}$ radyografi).

Figure ?. Radiolucent forcign hody covered with contrats anc dium in the ocsophag is ( $\mathrm{L} / \mathrm{L}$ radiography).

anamne\%inc dayanılarak alınan indirekt radyografi sonrasıncla kontrast madde ile sıvanmı̧ olarak izlendi (Şekil 2). Bu olguda perforasyon şüphesine karşı kontrası madde olarak urografin \%76 kullanıldı. Megaözefagus belijlenen bir olgula (\%l0) ise çckilen indirekı radyografi sonrasında örcfagusta dilatasyon belirlendi.

Mideyle ilgili lezyon bulunan 36 olgunun 14 'unde (\%.39) gastritis belirlendi. Gastritis bulunan bu olgularda midede kontrast madde kalıntısı ve mukozada düzensizlik saptand, (Şekil 3). Gastrik iilser belirlenen 7 olguda (\%19) ise mide mukozasında dolma fazlalığ (ülser nişi) belirlendi (Şekil 4). Pilorik obstruksiyon belirlenen $4 \mathrm{ol}$ guda (\%:11) kontrast maddenin 24 saat sonra dahi pilorustan geçişinin olmadığ belirlendi. Pilorus spazmlı 3 olguda $(\%: 8)$ indirekı radyografide kontrası maddenin mi-

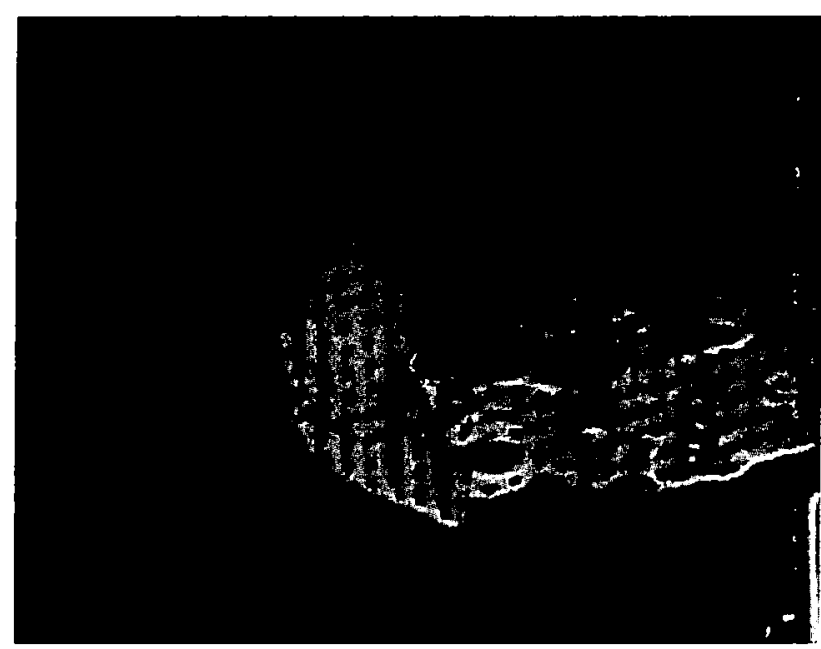

Şckil 3. Midede gastritis (L/L radyografi).

Figure 3. Gastritis in the stomach (1./l. radiography)

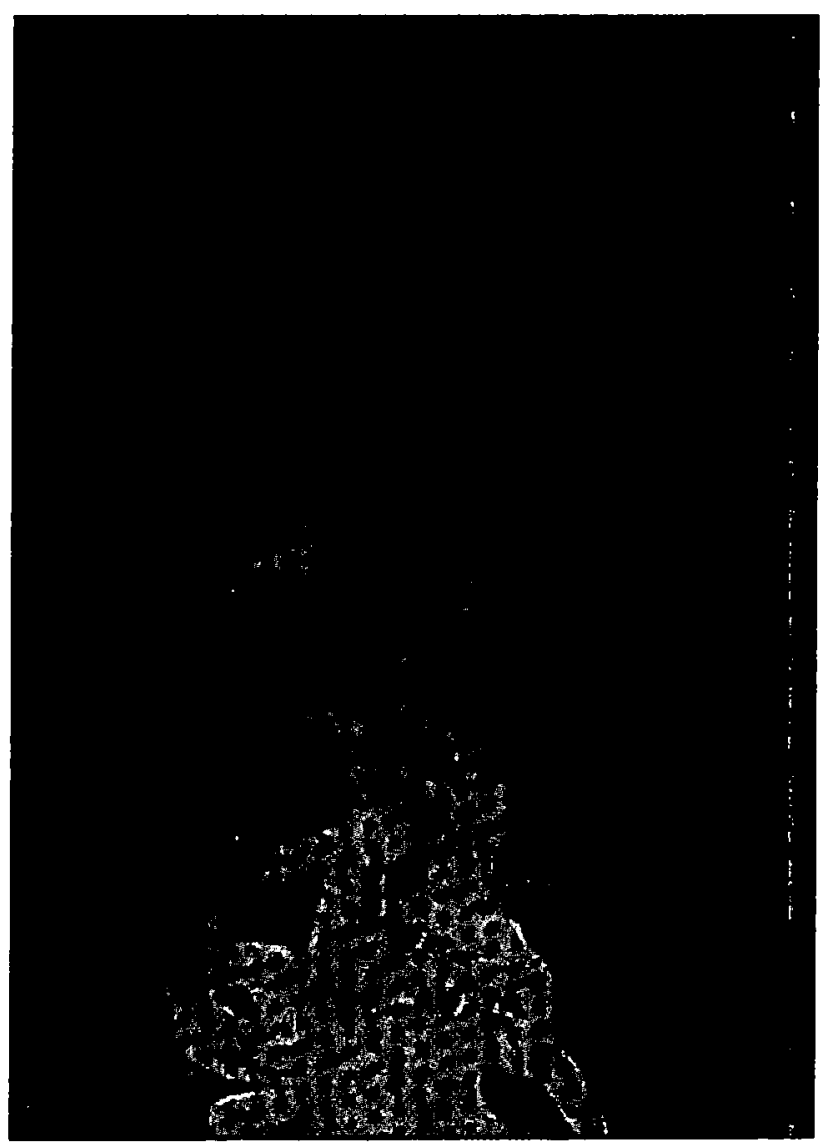

Şckil 4. Midede ülser nişi (V/D radyografi).

Figure 4. Uleer in the stomach (V/D radiography).

deden geçişinin sı\%ıntı tarzında olduğu göriildii. Gastrik dilatasyon bulunan 2 olguda (\%6) dircke radyogralide mdenin gazlı dilatasyonu izlendi. Sol latero lateral pozisyonda mide dilatasyonu belirlenen 3 olgunun sağlatero-lateral grafisinde pilorusun deplasmanı ortaya çıkarılẹı ve gastrik dilatasyon-volvulus tanıs kondu. Yabancı cisim belirlenen 3 olgunun 2'sinde direkl radyograli ile 


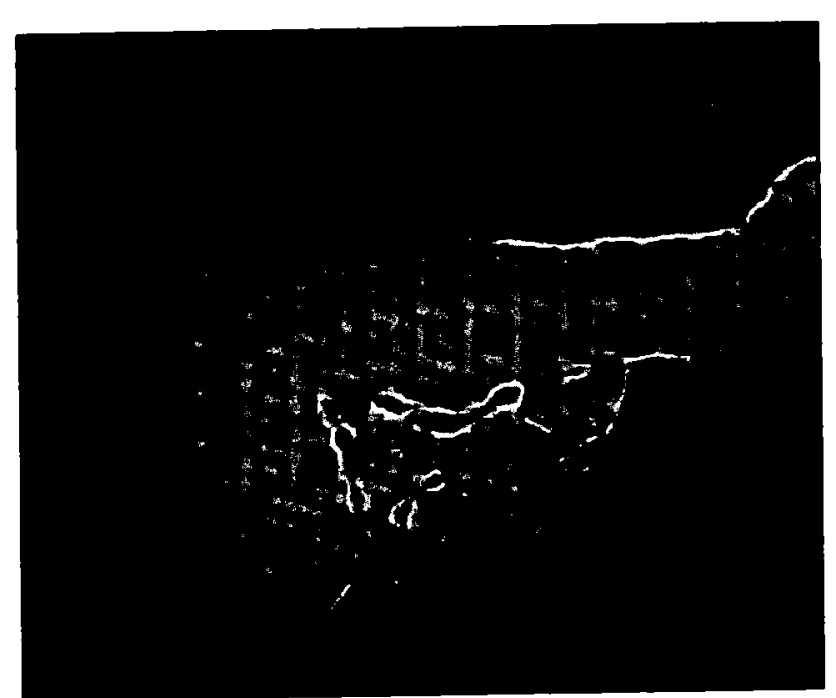

Sickil 5. Megakolon a l./L ridyograli).

Higure 5. Megacolon (1./L. radiography).

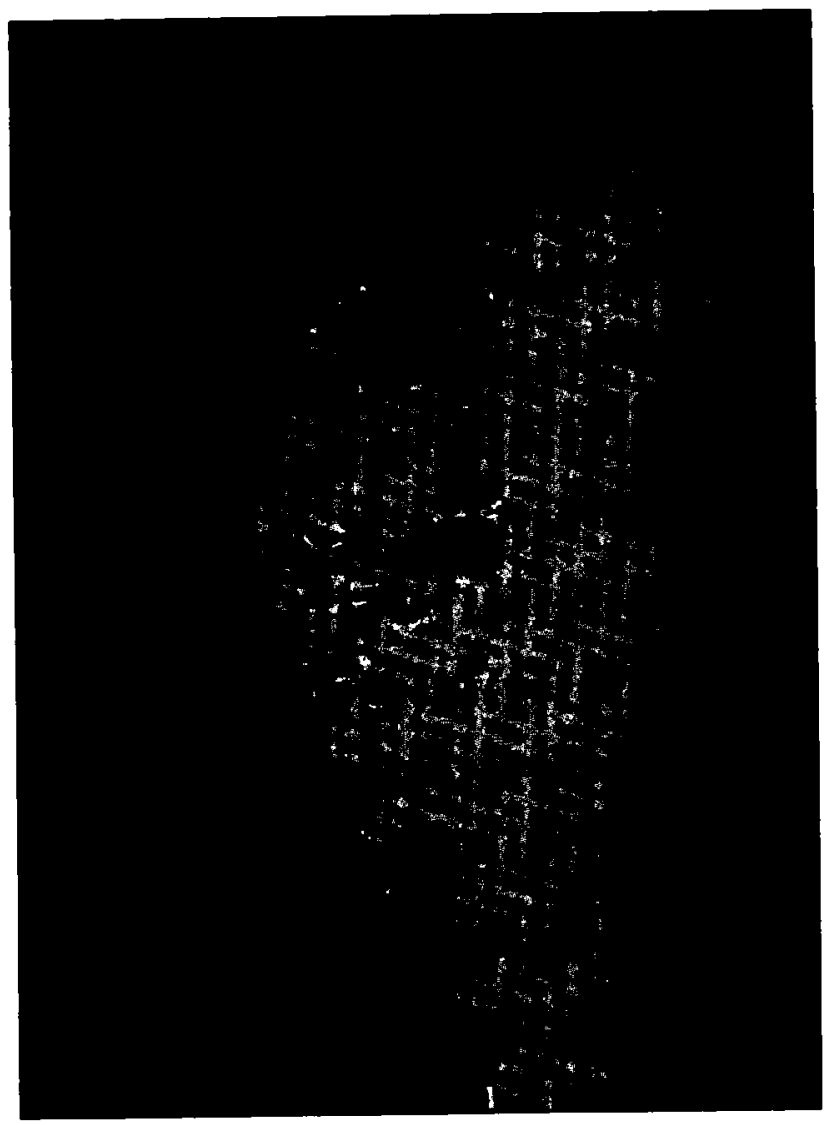

Sckil 6. Megatkolon (V/D radyografi).

Figure 6. Megacolon (V/D radiography).

radyoopak yabanci cisim tanmland. Bir olguda ise perforasyon şüphesine karşı Urografin \%76 ile alınan indirekt radyografi sonrasında radyolusent yabancı cisim kontläst madde ile sıvanmuş halde belirlendi.

Barsaklarla ilgili lezyon belirlenen 14 olgunun 9'unda (\%(14) megakolon (Şckil 5 ve 6) görüldü. Bu olgularda allnan indirckt radyografiden sonra kolonun 7. lumbal vertebranın çapından daha geniş olduğu görüldui. Hernia

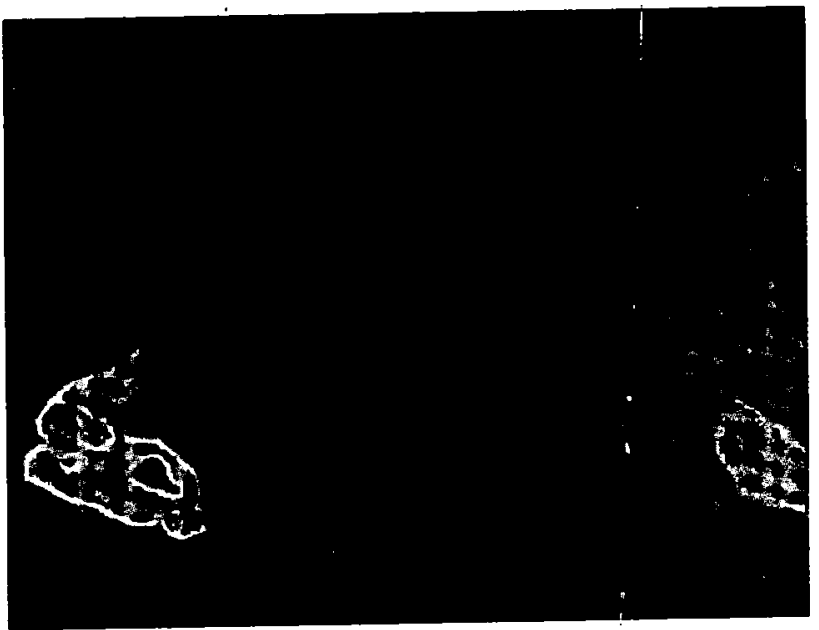

Sekil 7. Hernia diafragmatika ya bašgli olarak ince batsitklarm! gögüis boşluğunda. kalbin kranialine deplase olduğu grati (L./l. radyografi).

Figure 7. Smail intestine are deplaced to the cranial of the heart in the diaphragmatical hernia (L/L. radiography).

diafragmatika bulunan 2 olguda (\%14) uygulanan cheliografide ise ince barsaklar gögüs boşluğunda izlendi (Şekil 7). Rektum divertikülü şekillenen 1 olguda (\% 17) indirekt radyografi sonrasinda rektunda dilatasyon i\%lendi. Olgulardan 1 'inde $(\% 7)$ direkt radyografi sonucu barsaklarda yabancı cisim belirlendi. Bir olgudia da indirekt radyografi yardımıyla rektumda dolma defekli şeklinde ortaya çıkan kitlesel lezyon (tünür) tespit edildi.

\section{Tartışma ve Sonuç}

Sindirim kanalının radyografik muayenesinde direkl ve indirekt yöntemler kullanılmakıadır. Abcominal or. ganların pozisyonlarının tespit edilmesi. sindirim kanalın da herhangi bir opasitenin bulunup bulunmadığ turılnası ve uygun radyografik yöntemin seçilmesi amacıyla, daima direkı muayenenin, indirekı radyografik mu ayeneden önce yapılmasının gerektiği litcralürde belirlil. miştir $(2,10,13)$. Radyografide: ventro-dorsal, dorso-ventral. sağ latero-lateral. sol latero-lateral ve duruma göre bazen oblik pozisyonlarda grafilerin alınması gerektiğ bil dirilmektedir $(1,2,13,15,16)$. Çalışnada lïm olgularda once direkt radyografiler, bunu takiben de indirekt rildyografiler alind. Genel olarak sol latero-lateral ve ventrodorsal pozisyonda grafiler alındı. Sol latero-lateral vo ventro-dorsal grafide gastrik dilatasyon belirlenen 3 ol gunun sağ latcro-lateral grafisinde pilorusun deplasmanı ortaya çıkarıldı ve buna bağlı olarak gastrik dilatasyonvolvulus tanısı konuldu. Direkt grafi ile: 3 olguda $0 \%$. fagusta radyoopak yahancı cisim, 2 olguda midede gar h dilatasyon, 2 olguda midede radyoopak yabancı cisim ve 1 olguda da barsaklarda radyoopak yabanci cisim belirlendi. Indirekt radyografik muayene ile: 5 olguda $і z z e-$ 
fagitis, 1 olguda özefagusla radyolusent yabance cisim. 1 olguda megaczelagus, 14 olguda gastritis, 7 olguda gastrik iilscr. 4 ol guda pilorik obstruksiyon, 3 olguda pilorospa\%m, 3 olguda gastrik dilatasyon-volvulus, 1 olguda midede radyolusent yabanc1 cisim, 9 olguda megakolon, 2 olguda hernic diafragmatikaya bağlı olarak ince barsakların göğüs boşluğuna deplasmanı. 1 olguda rektum divertikülii ve 1 olguda da rektumda tümör belirlendi.

Sindirim kanalınm indirekt radyografisinde; pozitif kontrast. negatif kontrast veya çift kontrast radyografik muayene yöntemlerinden yararlanılması gerektiği ve amaca göre kontrast maddenin seçilmesinin uygun olduğu belirtilmcktedir (3,8-10,13). Sindirim kanalında perforasyondian şüphelenilen olgularda baryum suilfat yerine iodine preparatlarının kullanılması gercktiği, perfore bölgeden baryum siilfatun sıması durumunda irkilti ve graniilomatö\% yanğ oluşığ ifade cdilmektedir $(1,2.5,7,12)$ O]gularm tïmünde baryum suilfat ile pozitif kontrast radyografi ıckniğ kullanılmıştır. Çalışmada literatür verilerde önerildiğ gibi direkt radyogramlarda belirlenemeyen ancak anarnneze bağlı olarak yabancı cisim şüpheli olan 2 olguda perforasyona karş iyotlu preparatlar kullamılmışır

Sindirim kanalının radyografik muayenesinde; farenks. özclagus, mide. ince ve kalın barsakların sis tematik olarak incelenmesi gerektiğ bildirilmektedir (12.13). Tiim olgularda sistematik muayene sonucunda ozelagus. mide ve barsaklarda anormalitelere rastland.

Sindirim kanalına ait hastalıklarm, kusma. kilo kaybı. reguirgitasyon ve yutkunma güçlïği gibi klinik belirtilcrle ortaya f̧ıkığ bildirilmektedir $(10,12)$. Calışma malcryalini oluşıturan olgularda da bu tür klinik bulgular lespil edildi

Özefagus'tn radyografik muayenesi ile; megaözefagus, vaskuiler ring anomalileri, yabanct cisimler, özefagitis. özefageal neoplazma gibi anormalitelere rastlanıldı.̆ 1 ifade edilmektedir $(12,13,17)$. Olguların \%17'sinde örefagusla ilgili anormaliteyc rastlandı. Bu anormalitekrin \%50 sinin özefagitis, \%40\%n ozzefageal yabanc1 cisim ve \% $10^{\circ}$ unun da megaozefagus olduğu belirlendi.

Midenin radyografik muayenesi ile; pilorospazm, pilorik sicno\%, yabancı cisimler, gastritis, ülser, ncoplazmal ve mide rupturu gibi anormalitelerin belirlenebildiğ bildirilmiştir $(8,22,13,14)$. Olg̣uların \%60'unda mideye ilişkin anormaliteler belirlendi. Bu anormalitelerin \%39'unun gastritis. \%19'unun gastrik ïlser, \%1l'inin pilorik obstruksiyon, \%8'inin pilorospazm, \%8'inin gastrik dilatasyon-volvulus, '\%8'inin gastrik yabance cisim ve \%6's1nul da gastrik dilatasyon olduğu tespit edildi.
Barsaklarla ilgili olarak yabancı cisinler, lineer yabanci cisimler, nonülseratif ve iilseratif enteritis. invaginasyon, intramural kitleler (neoplazma. apse. granuloma), intestinal perforasyon, megakolon ve kolitis gibj anormalitelerin belirlenebileceği ifade edilmekledir (8.1214). Bu çalışmada. olguların $\% 23$ ünde barsiklarla ilgili anormalitelere rastland. Bu anormalitelerin \%64 ünum megakolon, \%14'ünün hernia diafragmalikaya bağlı olarak barsak deplasmanı. \% $17^{\circ}$ sinin reklum divertikiilii ve $\% 7$ 'sinin de rektum tümörüi olduğu belirlendi

Sonuç olarak; sindirim kanalı hastalıklarınıı lanısında direkt ve indirekt nuayeneler ile önemli bilgiler sağlanmaktadır. Dirckt grafinin sindirim kanals hastalıklarında, indirekt muayeneye göre yetersiz olduğ u, indirekt grafi ile sindirim kanalinda ohstruksiyon. dilatasyon, gastrik dilatasyon-volvulus, uilser, yangı. liimör. rotasyon ve pilorik hastalıklarm daha kolay değerlendirilebileceğgi ve kesin tanının sağ lanacağg kanısmal varıldı.

\section{Kaynaklar}

1. Agut $\Lambda$, Sanchez-Valverde $\mathbf{M N}$, I.asaosa JM, Marciano J, Molina F (1993): Use of iohexol as a gastrmintestinal medium in the dog. Vet Rad Uilt, 34. 171-177

2. Alkan Z (1999): Vetcriner Radyoloji. Millat Ajans Matbaacilik, Ankara.

3. Allan GS (1987): Radiologly of the digestive system. Aust Vet Prict. 17. 25-34.

4. Douglas SW, Herttage ME, Williams HJ) (1987): Pinciples of Veterinary Radiology: Fourth Fid. WB Silunders Company, Philadelphia.

5. Holland M (1993): Contrast agents. Vel Clin Nort Am: Small Anim Pract, 23, 269-279.

6. Jakovljevic S, Gibbs C (1993): Radiographic assessment of gastric mucesal fold thickness in dos. Am J Var Res. 54. $1827-1830$.

7. Özaydın I, Okumuş Z, Baran V. Kılı̨̧ E (1995): Kïpeklerde sodyum ve meglumine iothalamate Thelehti-3s; ile gastrointestinal radongati. KAU V $\mathrm{ct}$ Fak Derg. 1, 8995 .

8. Polese M, Bellenger CR, Maddison JE, Church DB (1991): Perforated gastric ulcer associated with pyloroplasty for chronic hypertrophic plofic sastropaty in a dog. J Small Anim Pract. 32. 355-358.

9. Saxon WD (1994): The acule abdemen. Vel Clin Non Am Sinall Auim Pracl, 24, 1208-1223.

10. Slatter D (1994): Textbook of Small Animal Surgery. Vol 1. WB Satunders Company. Philadelphia.

11. Sticle RL (1984): Positive-comtrast celiosisaly) (pertoneography) for the diagnosis of diaphragmanic hemia in desis. and cats. JAVMA, 185. 295-298.

12. Tams TR (1996): Handbook of Small Animal Gaisroenterology: WB Saunders Company. Philudelphiat.

13. Thrall DE (1994): Textbonk of Veterinary Diashnstle Radiology. $2^{\text {nd }}$ Edition. WB Saunders Company. Philadelphua 
14. Watters JW (1990): Radiography. 7-17. In: JD Hoskins (Ed), Veterinary Pediatrics: Dogs and Cats from Birth to Six Months. WB Saunders Company. Philadelphia.

15. Williams J, Biller DS, Miyabayashi $\mathbf{T}$, Leveille $\mathbf{R}$ (1993): Evaluation of iohexol as a gastrointestinal contrast medium in normal cats. Vet Radiol Ult, 34. 310-314.

16. Williams J, Biller DS, Myer CV, Miyabayashi T, Leveille $\mathbf{R}$ (1993): Use of iohexol as a gastrointestinal contrast agent in three dogs, five cats and one bird. JAVMA, 202, 624-627.
17. Yarım M, Gültiken ME, Öztürk S, \$ahal M, Bumin A (1999): Double aortic arch in a Sianese cat. Vet Pathol. 36. 34()-341.

Geliş tarihi: $26.1 .2001 /$ Kabul tarihi : 16.5 .2001

Yazışma adresi:

Dr. Ali Bumin

Ankara Universitesi Veteriner Fakultesi

Cerrahi Anabilim Dale

O6110 Diskapi, Ankara 